„TURYZM", t. 8, z. 1, 1998

Maciej Drzewiecki

\title{
POJĘCIE TURYSTYKI WIEJSKIEJ
}

NOTION DU TOURISME RURAL

\section{THE NOTION OF RURAL TOURISM}

W artykule zaproponowano zdefiniowanie pojęcia »turystyka wiejska« oraz przedstawiono formy turystyki wiejskiej.

W literaturze przedmiotu funkcjonuje, mniej lub bardziej powszechnie, szereg pojęć związanych bezpośrednio z rekreacją (turystyka) ${ }^{1}$ uprawianą na terenach pozamiejskich:

- turystyka wiejska (rural tourism),

- turystyka odbywająca się na obszarach wiejskich (country tourism),

- turystyka farmerska lub zagrodowa (farm tourism, Urlaub auf dem Bauernhof),

- agroturystyka (agrotourism),

oraz pojęcia szersze, jak turystyka ekologiczna, postindustrialna, alternatywna, czy zielona.

Do rzadziej spotykanych określeń, dotyczących turystyki luźniej związanej $\mathrm{z}$ terenami wsi, należą:

- turystyka rekreacyjna (aktywność o charakterze zdrowotnym),

- turystyka przyrodnicza (zwłaszcza poznawanie obszarów i obiektów chronionych prawem - parki narodowe i krajobrazowe),

- turystyka historyczna (poznawanie dziedzictwa narodowego),

- turystyka kulturowa (poznawanie życia innych środowisk społecznych)2.

${ }^{1}$ W artykule pominięto dyskusyjność zakresu pojęć: »turystyka - rekreacja«, stosując do analizowanej dziedziny nazwę »turystyka« zgodnie z brzmieniem używanym w relacjonowanych publikacjach anglojęzycznych.

2 Wg J. J. Pigrama (1991). 
Treści wymienionych pojęć nie są rozłączne, odwrotnie, cechuje je pewien stopień podobieństwa i zazębianie się ich zakresów znaczeniowych. Na podstawie literatury nie można jednak sformułować takich ich definicji, które byłyby w miarę powszechnie uznane w środowisku naukowym. W rozważanej sytuacji staje się konieczne dokonanie analizy logicznej treści interesujących nas pojęć. W tym celu można oprzeć się na kryteriach: formalnym, etymologicznym i funkcjonalnym.

Turystyka wiejska zarówno z etymologicznego, jak i formalnego punktu widzenia jest oczywiście ta, która odbywa się na terenach wiejskich. W tym miejscu natychmiast pojawia się trudność z określeniem pojęcia „wsi”. Formalnie rzecz biorąc tereny wiejskie są wyznaczone urzędowo, jako te, które mieszczą się $\mathrm{w}$ granicach odpowiednich jednostek podziału administracyjnego państwa; są to więc obszary nie wchodzące w obręb miast. To kryterium formalne zostało jednak już dawno podważone przez J. K o s t r o w i c k i e go (1976), który wysuną kryterium funkcjonalne, uznając za tereny wiejskie obszary polożone między miastami wydzielonymi. Na terenach tych przeważa rolnictwo, leśnictwo, rybołówstwo oraz rekreacja wraz ze związanymi z tym funkcjami: przetwórstwem, osadnictwem, usługami i urządzeniami infrastruktury technicznej.

Ujęcie powyższe nie wystarcza jednak dla określenia ram przestrzennych dla turystyki wiejskiej, gdyż wyznaczone w ten sposób obszary mogą posiadać cechy utrudniające, lub wręcz uniemożliwiające uprawianie turystyki, której jednym z celów jest odtwarzanie i pomnażanie sił duchowych i fizycznych człowieka. Cechy te związane są z istnieniem w samej wsi, lub w blisko położonych miastach, obiektów zagrażających zdrowiu i dobremu samopoczuciu, a także z koncentracją ludzi, budowli i pojazdów.

Uwarunkowań powyższych nie uwzględnia także znana definicja Brytyjskiej Rady Turystyki, uznająca, że dla celów praktycznych określenie »wieś« (okolica wiejska - country side) odnosić można do „wszystkich rolnych, leśnych i innych terenów otwartych, łącznie z osadzonymi tam wsiami i małymi miastami, poniżej 10 tys. mieszkańców” (G i l b e r t, T u n g 1989). Szeroki zakres tej definicji sprawia, że obejmuje ona nie tylko tereny „uznane za wiejskie”, ale także w różnym sensie i różny sposób zdegradowane, uprzemysłowione i przez to źle oddziałujące na zdrowie i psychikę ludzi.

Rozwiązanie tego dylematu tkwi w zaproponowanym przez H. G rolI e a u i A. R a m u s a (1986) podziale przestrzeni wiejskiej na dwie części:

1) tereny podmiejskie, zurbanizowane i uprzemysłowione, $z$ dużym udziałem zatrudnienia pozarolniczego, gdzie rolnicy stanowią zdecydowaną mniejszość;

2) głęboką wieś (, prawdziwą), oddaloną od miast, bardziej rolniczą, z mało skażonym środowiskiem przyrodniczym.

Precyzując bliżej pojęcie „głębokiej wsi” ze społeczno-ekonomicznego punktu widzenia należałoby wskazać takie cechy, jak:

- niska gęstość zaludnienia, 
- niski poziom urbanizacji (mierzonej wskaźnikami funkcjonalnymi, np. udziałem ludności pozarolniczej),

- przewaga działalności rolniczej,

- niski poziom uprzemysłowienia, co w efekcie wyraża się cechami korzystnymi dla wypoczynku: dobrym stanem środowiska przyrodniczego, atrakcyjnym, harmonijnym krajobrazem kulturowym, ograniczoną liczbą turystów, ciszą i spokojem, a nierzadko wartościowymi elementami regionalizmu i folkloru.

W regionach górskich tereny zaludnione nie posiadają wszystkich wymienionych cech (np. mają niski udział rolnictwa), ale mają je sąsiadujące obszary przyrodnicze i one stanowią tereny turystyczne.

Uwypuklenie cech ,głębokiej wsi”, dokonane wyżej, wskazuje jednocześnie, że nie mamy na myśli ,prawdziwej” wsi w rozumieniu zacofania, biedy i prymitywnej gospodarki jako jej symptomów, gdyż taka wieś w Polsce praktycznie nie istnieje, lecz wieś pozbawioną czynników utrudniających wypoczynek.

Jeżeli zgodzimy się z prezentowanym ujęciem zakresu przestrzennego wsi, stanowiącej obszar, na którym odbywa się turystyka wiejska, to należy skonfrontować je z kryterium funkcjonalnym i określić, jakie formy turystyki mogą egzystować w tym środowisku, a jakie nie.

Głęboka wieś to zapewne obszar wędrówek, wycieczek krajoznawczych i turystyki specjalistycznej (choć nie każdej, bo trudno uznać, że wycieczki wysokogórskie odbywają się na terenach typowo wiejskich), natomiast pobyty w dużych, zurbanizowanych miejscowościach wczasowych, choćby miały formalnie status wsi (np. Charzykowy) lub w luksusowych hotelach i pensjonatach, nastawionych na utrzymanie klientów przez całą dobę w obrębie kompleksu hotelowego - raczej nie.

Wśród definicji używanych w literaturze przedmiotu dla sprecyzowania analizowanego tu pojęcia, najbardziej lapidarne są te, które określają turystykę wiejską jako różnorodne formy wypoczynku, rozwijające się na obszarze wsi ( $\mathrm{m}$. in. B a r b i e r 1991). Podobne stanowisko zajmuje M. Jansen-Verbeke, która „turystyką na obszarach wiejskich” obejmuje „wycieczki, turystykę wędrowną po okolicach wiejskich (samochód, rower, łódź, koń), jak również wakacje pobytowe $[\ldots]$ w wiejskich hotelach, na kempingach, w wioskach wakacyjnych, pensjonatach i kwaterach prywatnych" (J a n s e n - V e r b e k e 1990, s. 41), a więc prawie wszystko, co może dziać się, z naszego punktu widzenia, na wsi.

Rozwinięte koncepcje i definicje podaja $\mathrm{m}$. in. Bernard Lane oraz E. T. Davies i D. C. Gilbert. Pierwszy z nich przeciwstawia się lapidarnym ujęciom: „ekologiczna turystyka wiejska to nie jest po prostu wypoczynek zlokalizowany na wsi; ma ona szereg kluczowych cech", wśród nich zaś autentyczność, osobiste kontakty z ludźmi i środowiskiem przyrodniczym, udział w życiu wsi i szereg 
innych ( $\mathrm{L}$ a n e 1992a). W tym miejscu, rozważając szeroko, czym jest w istocie turystyka wiejska, zauważa trafnie, że „nie tylko ma ona miejsce na wsi, lecz »wiejskość« jest jej centralnym punktem”, po czym uściślając ten pogląd dodaje, iż obejmuje ona nie tylko wakacje na farmie ale również ekoturystykę, spacery, wspinaczkę, turystykę rowerową i zdrowotną, przygodę, podróże krajoznawcze, poznawanie dziedzictwa narodowego oraz turystykę etniczną ( $L$ a n e 1992 b, s. 4). W ostateczności, w opracowaniu firmowanym przez OECD (Tourism Strategies... 1993, s. 32) formułuje następującą definicję: „turystyka wiejska jest tą, która zlokalizowana jest na terenach funkcjonalnie wiejskich, a fundamentalne znaczenie mają dla niej specyficzne cechy wiejskiego świata przestrzeni otwartych, kontakty $z$ natura, wiejskim dziedzictwem i społeczeństwem".

Podobne myśli, sformułowane jednak nieco szerzej, zawiera definicja M. Drzewieckiego z 1995 r.: „Turystyka wiejska stanowi formę rekreacji odbywającej się na obszarach »prawdziwej wsi« $\mathrm{i}$ obejmuje wielorakie rodzaje aktywności rekreacyjnych związanych z przyroda, wędrówkami, turystyką krajoznawcza, zdrowotną, kulturową i etniczną" (D r z e w i e c k i 1995, s. 22). Dzisiaj skłonny jestem wyłączyć z tej definicji turystykę zdrowotną, kojarząca się z pobytami (a więc nie turystyka) szpitalno-sanatoryjnymi, które nie mają żadnego związku z wsią, a ponadto dalekie są od dobrowolności, stanowiącej jedno z kryteriów turystyki w ogóle, a także turystykę etniczna, która może dotyczyć zarówno miast, jak i wsi. Po tych korektach oraz uzupełnieniu o kryterium funkcjonalne, proponowana definicja brzmi: „Turystyka wiejska stanowi formę rekreacji odbywającej się na terenach „prawdziwej wsi”3 $\mathrm{i}$ wykorzystującej jej specyficzne walory i zasoby, obejmując wielorakie rodzaje aktywności rekreacyjnych związanych z przyroda, wędrówkami, krajoznawstwem i poznaniem wsi”.

Definicja nie obejmuje położonych na wsi zurbanizowanych miejscowości wczasowych oraz turystyki specjalistycznej, odbywającej się na terenach chronionych (parki narodowe) lub nie mających charakteru wiejskiego (tereny wysokogórskie), a także wszystkich rodzajów aktywności rekreacyjnych na terenach podıniejskich (np. ogródki działkowe, ośrodki wypoczynku świątecznego). Nie obejmuje więc - co najważniejsze - całości wypoczynku ani wszystkich terenów pozamiejskich. Tym samym jej treść jest całkowicie różna od określenia „turystyki na terenach wiejskich”, które zresztą - z punktu widzenia prezentowanych wywodów i ich logiki jest zbędne, a merytorycznie chybione, gdyż byłoby wyłącznie formalistyczne, a obejmowałoby zjawiska i formy zagospodarowania tak różne, jak np. stanice wodne i motele przy drogach ekspresowego ruchu, czy luksusowe hotele i kwatery agroturystyczne.

3 Poprawne, choć mniej jednoznaczne, byłoby alternatywne zastosowanie w treści definiçji pojęcia ,wsi w znaczeniu funkcjonalnym", które nie spelniałoby jednak wszystkich wskazanych poprzednio cech środowiska wiejskiego sprzyjającego wypoczynkowi. 
Reasumując - w prezentowanym ujęciu, uwzględniającym stanowiska innych autorów i własne, turystykę wiejską stanowią jej typowe formy, które nie mają sensu istnienia gdzie indziej, niż na terenach „prawdziwej wsi”: agroturystyka, wędrówki piesze, konne, kolarskie i motorowe.

$\mathrm{Na}$ terenach o formalnym statusie wiejskim, lecz poza "głęboką wsią" rozwijają się: alpinizm (taternictwo), wędrówki górskie, pobyty uzdrowiskowe, pobyty $w$ hotelach wypoczynkowo-rozrywkowych $i$ inne; nie są one turystyką wiejską.

Ponadto istnieją formy, które mogą egzystować w obrębie „głębokiej wsi”. Stanowią wtedy część turystyki wiejskiej, gdy trasa biegnie przez różnego typu tereny wiejskie: turystyka wodna, turystyka pielgrzymkowa, wycieczki przyrodoznawcze oraz pobyty wczasowe.

Operując pojęciem ,produktu turystycznego”, dla turystyki wiejskiej jego rdzeniem są: środowisko przyrodnicze oraz dziedzictwo kulturowe (sztuka ludowa, zwyczaje, obchody świąt, architektura regionalna, wiejski sposób zagospodarowania wsi i zagrody oraz inne). Wokól rdzenia rozbudowana jest usługowa część produktu: zakwaterowanie w obiektach o charakterze tradycyjnym, regionalna kuchnia i transport, wypożyczalnie sprzętu, stadniny. Tak skonstruowany wiejski produkt turystyczny, zgodnie z założeniami strategii rozwoju (opracowanej dla Polski przez ekspertów Unii Europejskiej), może stać się tzw. produktem markowym (M a j e w s k i 1997).

Na marginesie rozważań pojęciowych warto przytoczyć oficjalną opinię Komisji Unii Europejskiej z 1990 r., która w raporcie dotyczącym wyników promocji turystyki wiejskiej stwierdza: „w Europie nie istnieje żadna precyzyjna definicja turystyki wiejskiej, a nawet środowiska wiejskiego [...] formy tego zjawiska są różnie postrzegane w poszczególnych krajach [...] najczęściej jednak występuje pod etykietką »taniej turystyki«" (Community 1992).

\section{PIŚMIENNICTWO}

B a r b i e r B., 1991, Turystyka na obszarach wiejskich we Francji, Acta Univ. Lodz., Folia geogr., z. 14.

Community Action to Promote Rural Tourism. Communication from the Commission, [w:] Tourism on the Farm, 1992, Environmental Inst., University College, Dublin.

D a v i e s E. T., G i I b e r t D. C., 1992, A Case Study of the Development of Farm Tourism in Wales, Tourism Management, March.

D r z e w i e c k i M., 1995, Agroturystyka. Zatożenia-uwarunkowania-dziatania, Inst. Wyd. "Świadectwo", Bydgoszcz.

G i 1 b e r t D., T u ng L., 1990, Public Organizations and Rural Marketing Planning in England and Wales, Tourism Management, June.

G r o ll e a u H., R a mus A., 1986, Espace rural, espace touristique le tourisme à la campagne et les conditions de son développement en France, La Documentation française, Paris. 
J a n s e n - V e r b e k e M., 1990, Znaczenie turystyki na obszarach wiejskich w Europie, Probl. Turystyki, $\mathrm{nr} 1 / 2$.

K o st row i c k i J, 1976, Obszary wiejskie jako przestrzeń wielofunkcyjna, Przegl. Geogr., z. 4 .

L a n e B., 1992a, A Philosophy for Rural Tourism, [w:] Tourism on the Farm, Environmental Inst., University College, Dublin.

L a n e B., 1992b, A Review for the Organization for Economic Co-operation and Development, Rural Tourist Unit, University of Bristol.

M a j e w s k i J., 1997, Koncepcja tworzenia produktów markowych w turystyce wiejskiej (materialy konferencyjne), Centrum Doradztwa i Edukacji w Rolnictwie, Kraków.

P i g r a m J. J., 1991, Planning for Tourism in Rural Australia Bridging the Policy Immplentation Gap.

Tourism Strategies and Rural Development, 1993, Organization for Economic Co-operation and Development, Tourism Committee, Paris.

Dr hab. Maciej Drzewiecki, prof. ATR

Katedra Ochrony i Ksztaltowania Środowiska

Wplynęlo:

Zakład Gospodarki Przestrzennej

ul. Sucha 9

85-796 Bydgoszcz

\section{RÉSUMÉ}

Dans l'article, on a présenté la proposition de définir la notion „tourisme rural” (rural tourism). Du point de vue formel, on pourrait le caractériser comme celui qui a lieur sur les terrains ruraux. Cependant ces terrains au sens administratif (donc tous ceux hors de la ville) embrassent des étendues, qui ne favorisent pas le repos, ou bien le rendent impossible eu égard aux effets qui peuvent nuire à la santé. Ce sont les terrains industrialisés ou urbanisés, quoique formellement ruraux.

En connection avec ce fait, en s'appuyant sur G r o l l e a u et R a m u s (1986), on a adopté l'opinion, que le tourisme rural est celui, qui profite de tous les traits de la campagne et ne se fait que sur ces terrains ruraux, qu'on peut définir comme campagne „profonde” et „vraie”. Les traits de celle-ci sont: la densité basse de la population, le niveau peu élevé de l' urbanisation, la prépondérance de l'activité agricole et le niveau bas de l'industrialisation. Les terrains mentionnés doivent favoriser le repos par le bon état du milieu naturel, le paysage culturel attrayant et harmonieux, le silence et la tranquillité, le mouvement des personnes et des véhicules très limité.

La définition qu'on propose est comme suit: Le tourisme rural constitue une forme de récréation (partant du principe que toute récréation est une notion principale, embrassant toutes les formes du repos actif et passif) se faisant sur les terrains de la „vraie campagne” et exploitant ses valeurs et ressources spécifiques, prenant en considération les genres variés des activités de récréation liés à la nature, aux tours, à la chorographie et à l'approche des problemes rustiques.

La notion ainsi définie ne comprend pas les grandes localités de repos urbanisées, même si elles comptent parmi les villages, ni les excursions au sein de la nature dans les Parcs Nationaux ou celles en montagne, ni l'alpinisme et les séjours dans les hôtels de repos et de distraction situés à la campagne. Elle ne prend pas, non plus, en considération les activité de récréation sur les terrains suburbains fortement développés et intensivement aménagés. 
Les formes primordiales du tourisme rural sont: agrotourisme, promenades à pied, à cheval, à bicyclette, à vélomoteur.

Traduit par Lucjan Kowalski

\section{SUMMARY}

The article presents an attempt to define the term 'rural tourism'. Formally, it could be defined as one which occurs in rural areas. These areas, however, from the administrative point of view, also comprise areas with features which are unsuitable for resting or even make it impossible because of their harmful effect on human organism. They are industrialized and urbanized areas, though formally they remain rural.

Consequently, following H. G r o $1 \mathrm{l} \mathrm{e} \mathrm{a} \mathrm{u} \mathrm{and} \mathrm{A.} \mathrm{R} \mathrm{a} \mathrm{m} \mathrm{u} \mathrm{s} \mathrm{(1986),} \mathrm{it} \mathrm{was} \mathrm{assumed} \mathrm{that}$ rural tourism, that is such which makes use of country features, occurs only in this part of rural areas which can be described as 'genuine' country of the following characteristics: low density of population, a low level of urbanization, agricultural activity predominating, and a low level of industrialization. Such areas should possess features beneficial for recreation: good condition of the natural environment, attractive, harmonious cultural landscape, peace and quiet, small human and car traffic.

The following definition has been proposed: rural tourism is a form of recreation (considering that recreation is a primary term, comprising all forms of passive and active recreation), which occurs in the 'genuine country' areas and makes use of its special values and resources, covers all kinds of recreational activities related with nature, walking, tramping and familiarizing with the country. A definition constructed in this way comprises neither big, urbanized recreational places, which formally might have the status of villages, nor nature trips in National Parks, mountain excursions and mountaineering, nor stays at the hotels (recreation and entertainment) situated in the country. It does not refer to various recreational activities in suburban areas, which are well developed economically. cycling.

The main forms of rural tourism are: agro-tourism, walking, horse-riding, cycling and motor- 